\title{
Corrosion Behavior of Three Nanoclay Dispersion Methods of Epoxy/Organoclay Nanocomposites
}

\author{
Wiwat Keyoonwong, ${ }^{1}$ Yi Guo, ${ }^{1}$ Masatoshi Kubouchi, ${ }^{1}$ Saiko Aoki, ${ }^{1}$ and Tetsuya Sakai ${ }^{2}$ \\ ${ }^{1}$ Department of Chemical Engineering, Tokyo Institute of Technology, 2-12-1 Ookayama, Meguro-ku, Tokyo 239-8686, Japan \\ ${ }^{2}$ Department of Industrial Engineering and Management, Nihon University, 2-1, Izumi-cho 1-chome, Narashino-shi, \\ Chiba 275-8575, Japan
}

Correspondence should be addressed to Wiwat Keyoonwong, te_tee-tu@hotmail.com

Received 23 May 2012; Revised 11 September 2012; Accepted 25 September 2012

Academic Editor: Leila Dhouibi

Copyright (c) 2012 Wiwat Keyoonwong et al. This is an open access article distributed under the Creative Commons Attribution License, which permits unrestricted use, distribution, and reproduction in any medium, provided the original work is properly cited.

The aims of this study, firstly, to obtain high degree of clay exfoliation in the epoxy matrix by three dispersion methods such as normal mixing, shear mixing, and high-speed mixing and, secondly, to investigate corrosion behavior of epoxy/organoclay nanocomposite, immersion test, weight change, and penetration behavior were conducted. From the three mixing methods, the high-speed mixing method showed larger clay interlayer distance, smaller clay aggregate, and more homogeneity and expectedly resulted in high anticorrosive properties. Penetration depths of these nanocomposites showed a small difference; however, the most noticeable improvements in anticorrosion performance for epoxy/organoclay nanocomposites under high-speed mixing method were found to reduce penetration and weight uptake which are described via the model of nanoparticulate-filled structure and discussed in corrosion protection mechanism against environmental liquid penetration.

\section{Introduction}

Polymer-layered silicate nanocomposites (PLSNs), materials consisting of a polymer matrix reinforced with inorganic nanoparticles, are an expanding field of study due to unexpected improvement on mechanical, thermal, and barrier properties over conventional unfilled polymer resins. Due to the property enhancement at small clay loading (1-10 wt\%), PLSNs have attracted increasing interest from scientific [1-3] and industrial [4] perspectives.

Montmorillonite (MMT) is one of the most common inorganicfiller. MMT, which has an alumino-silicate structure, consists of two tetrahedral layers sandwiching an octahedral layer with $\mathrm{Na}^{+}$or $\mathrm{Ca}^{2+}$ ions residing in the layer. Several PLSNs have successfully been prepared using MMT with polyamide as the most successful matrix [510]. Typically, the unparalleled ability of smectic clay to boost the mechanical properties of an engineering plastic was first demonstrated in a stunning example by Toyota researchers [11-13]. By replacing the hydrophilic $\mathrm{Na}^{+}$and $\mathrm{Ca}^{2+}$ cations of the native clay with a more hydrophobic organic onium ion, they were able to intercalate and polymerize $\varepsilon$-caprolactam in the interlayer (gallery) region of the clay to form a nylon-exfoliated clay hybrid composite. At a loading of only 4.7 mass $\%$ of clay, the modulus is raised by $40 \%$, the strength is increased by $50 \%$, and the heat distortion temperature is increased by $80^{\circ} \mathrm{C}$ compared with the neat polymer, respectively. The key to this extraordinary performance of nylon 6-clay hybrids is the complete dispersal (exfoliation) of the clay nanolayers in the polymer matrix.

In the past decades, mechanism of clay dispersion into the epoxy matrix has been one of the most interesting issues of polymer research. Sancaktar and Kuznicki [14] proposed stages of dispersing nanoparticles in polymeric matrices: (1) intercalation of particles by polymer chains, (2) flow-induced exfoliation of individual particles, and (3) homogeneous dispersion of exfoliated particles into the matrix. The first stage is governed by clay pretreatment. The last two stages are controlled by mixing. Sancaktar and Kuznicki [14] studied organomagadiite intercalates, interlayered by various onium ions, to form epoxy-layered silicate nanocomposites. After treatment, the nanolayers 
were spaced over long distances at $80 \AA$ Bragg spacing. According to the article [14], polymerization of monomers in the galleries of protonated onium ion exchanged form of smectic clays during intercalation stage is necessary for synthesis of amine-cured epoxy nanocomposites. Vaia et al. [15] implied that the degree of exfoliation would be improved through the aid of shear devices in the mixing process.

However, PLSNs using MMT with epoxy resin as the matrix have not convincingly proved to be a complete exfoliation of the layered structure in the epoxy matrix. Epoxy resins are characterized by the presence of epoxide rings which can be reacted with curing agents or catalytically homopolymerize to form a crosslinked polymeric structure. Crosslinked epoxies exhibit outstanding properties such as good adhesion to a variety of surfaces, low shrinkage during curing, no emission of volatile products, resistant to thermal and chemical attack, high glass temperature, and high mechanical modulus.

These intercalated organoclay/epoxy nanocomposites show improved properties including enhanced mechanical properties at low nanofillers loading [16, 17], increased thermal property [18], and improved corrosion performance [19, 20]. Ngo et al., [21] reported that epoxy/clay nanocomposite via high-speed mixing device showed that strain energy release rate was increased 130 times more than original epoxy, $100 \mathrm{~J} / \mathrm{m}^{2}$.

Focusing on corrosion studies, there are still few articles publish about it. Rana et al. [22] studied moisture diffusion through neat vinyl ester resin containing nanoclay and illustrated that "montmorillonite clay was effective in reducing the diffusion coefficient of water through the vinyl ester resin." His diffusion experiments revealed that the advantage of incorporating the clay was dramatic for diffusion at elevated temperatures as for the diffusion of distilled water at $42.5^{\circ} \mathrm{C}$, with $\mathrm{D}$ going down from 16.43 $\times 10^{-13}$ to $0.93 \times 10^{-13} \mathrm{~m}^{2} / \mathrm{s}$. In a previous corrosion study on epoxy/clay nanocomposites in our laboratory [23], intercalated organoclay/epoxy nanocomposites showed better corrosive resistance compared to neat epoxy resin.

The main goal of this study is to obtain the optimum clay dispersion method into epoxy matrix via three different mixing methods and to study corrosion behavior of epoxy/organoclay nanocomposites under immersion test, from weight change and penetration behavior points of view.

\section{Experimental Method}

2.1. Materials. Epoxy composites used in this study were bisphenol A type (Epomik R140) from Mitsui Chemical Co., Ltd, diamine curing agent (Jeffamine D230) from Huntsman Corporation, and montmorillonite-based organoclay (Nanomer I.30E) from Nanocor Inc., USA, employed to produce the nanocomposites.

2.2. Method. Epoxy/organoclay nanocomposites were prepared at various conditions. Initially, epoxy and 1 part per hundred resin (phr) of organoclay were mixed via three

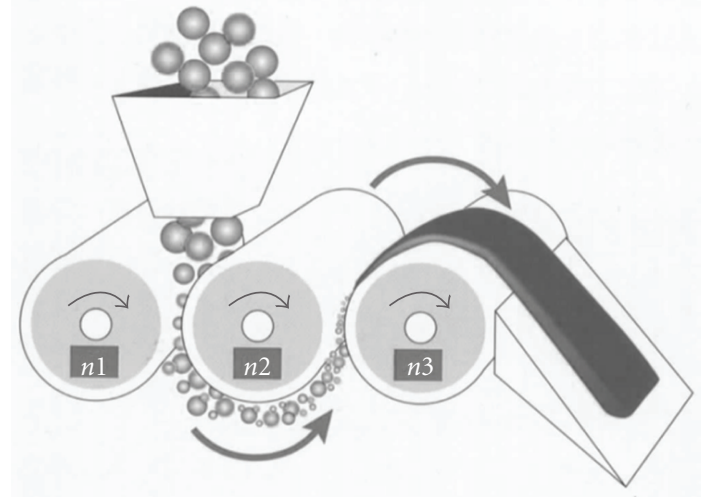

FIGURE 1: Illustration of mixing mechanism by three-roll calender.

different mixing methods: (1) normal mixing at 1,000 rpm via propeller mixer for three hours, (2) shear mixing via three-roll calender (EXAKT 50, Exakt $\mathrm{GmbH}$ ) for three times as shown in Figure 1 followed by high-speed mixing at 11,000 rpm for three hours, and (3) high-speed mixing at 20,000 rpm via homogenizer (Ultra-TURRAX T18, IKA.) for three hours as shown in Figure 2. After mixing according to the conditions, the mixtures were degassed under vacuum for 10 minutes. Thereafter, they were cooled down to room temperature, and then the corresponding curing agent was added to the mixtures stirred with degassing again for 10 minutes before casting. The ratio of resin to hardener kept as $100: 30$. Finally, the resin mixture of epoxy with diamine was cured at $80^{\circ} \mathrm{C}$ in oven for six hours and followed by post curing at $120^{\circ} \mathrm{C}$ in oven for 12 hours.

\subsection{Degree of Nanoclay Intercalation/Exfoliation and Compos- ite Morphology}

2.3.1. Interlayer Distance ( $d$-Spacing). Interlayer distance ( $d$ spacing) of organoclay (montmorillonite) was measured using a Philips MRD X'Pert with a rotation anode and $\mathrm{CuK} \alpha$ radiation $(\lambda=1.5418 \AA)$. The scanning range was from $1.05^{\circ}$ to $9.95^{\circ}$. The step size was $0.02^{\circ}$ and the step time was $3 \mathrm{sec}$ for the measurement of the $d$-spacing. The $d$ spacing of different mixing conditions were investigated. For the analysis of the clay powder, particles were mounted on a sample holder with a large cavity, and a smooth surface was obtained by passing the particles with a glass plate. Analysis of organoclay swollen in the epoxy resin with the curing agent was performed by spreading the sample composites on the sample holder. The nanocomposite plates produced during the molding process had a fairly smooth surface which has been directly analyzed.

The organophilic nature of the clay allows the dispersion of organic solvent or monomer between the clay layers. XRD measurement can be used to characterize the interlayer distance. If diffraction peaks were observed in the low-angle region, such peaks would indicate the $d$-spacing of ordered intercalated and exfoliated (delaminated) nanocomposites.

2.3.2. Morphology. The nanoclay composite structure and clay distribution were examined using transmission electron 


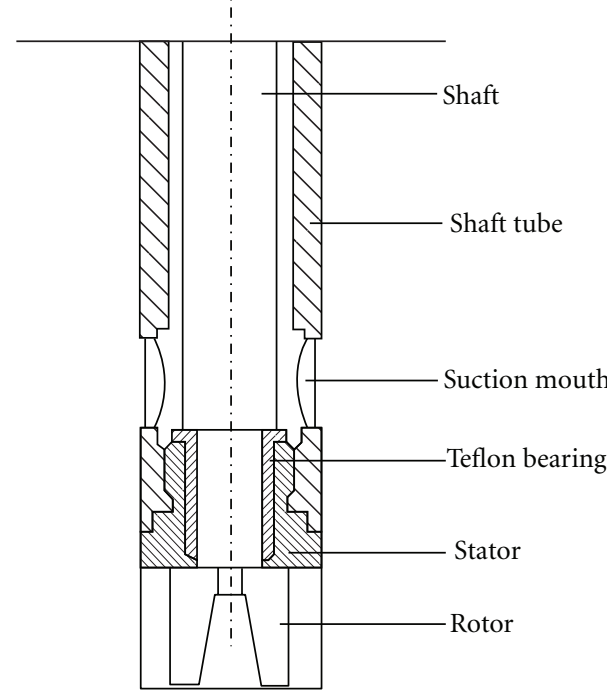

(a)

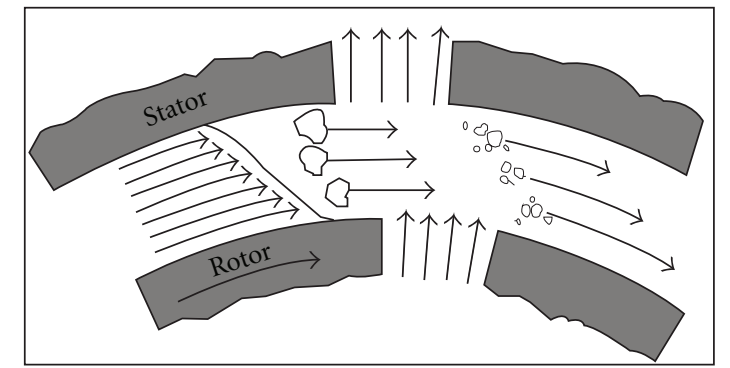

(b)

FIGURE 2: Cross-section of high-speed homogenizer (a) and mechanism of rotor-stator (b).

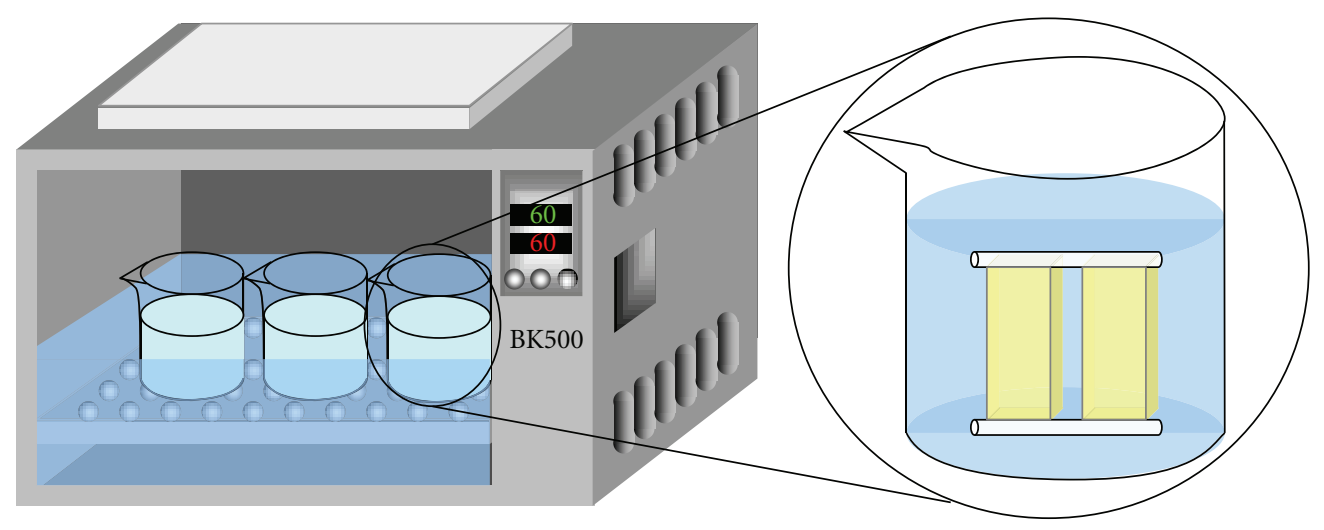

Figure 3: Typical apparatus of immersion test.

microscopy (TEM). TEM images were obtained by a JEOL $2010 \mathrm{~F}$ equipped with a field emission gun operating at $200 \mathrm{kV}$. TEM samples were prepared by ultramicrotome to be thin sections of the polymer nanocomposite with a diamond knife. These thin sections were then captured on coated $\mathrm{Cu}$ grids. The samples were tested at different magnifications from $0.5 \mu \mathrm{m}$ to $20 \mathrm{~nm}$ scale bar.

\subsection{Corrosion Behavior}

2.4.1. Immersion Test. The immersion test specimens of 60 $\times 25 \times 2 \mathrm{~mm}^{3}$ for measurement of initial weight were dried at $50^{\circ} \mathrm{C}$ in oven for more than 75 hours according to the previous study [23]. All specimens holding with a Teflon tube, in order to avoid sample overlapping, were tested in beakers containing $10 \%$ of sulfuric acid solution. The beakers were sealed with plastic film to avoid evaporation of the solution. The immersion tests were conducted in water bath controlled at $60^{\circ} \mathrm{C}$ as shown in Figure 3 .
2.4.2. Weight Change Measurement. Specimens were removed at regular time intervals, washed by water, and then carefully wiped to remove excess of acid on the specimens. A microbalance was used for measuring the specimen weight. The weight change was determined by obtaining the change in mass of specimen in 10 different times from $0 \mathrm{~h}$ up to $625 \mathrm{~h}$, relative to the initial weight, and was calculated by

$$
M_{t}=\frac{W_{t}-W_{0}}{W_{0}} \times 100 \%
$$

where $M_{t}=$ weight gain $(\%), W_{0}=$ initial weight of dry sample $(\mathrm{g})$, and $W_{t}=$ weight of wet sample $(\mathrm{g})$.

2.4.3. Penetration Behavior. To observe and measure penetration depth and penetration profile of sulfur (S) element of epoxy/organoclay nanocomposites, energy dispersive Xray spectroscopy (EDS) is an analytical technique used for the elemental analysis of samples. Energy dispersive X-ray 
Penetrated layer at sampling time (meter)

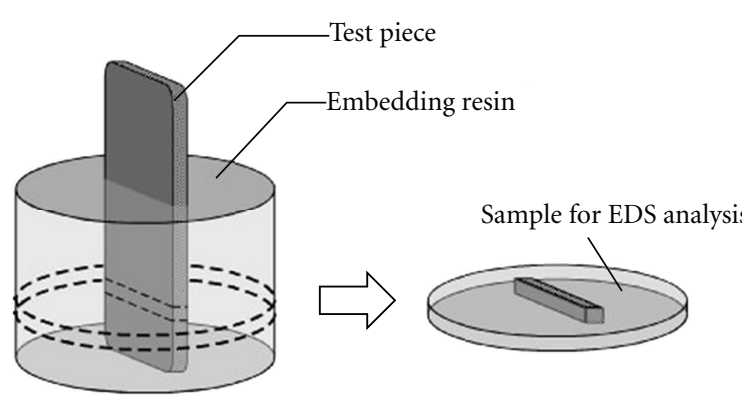

(a)

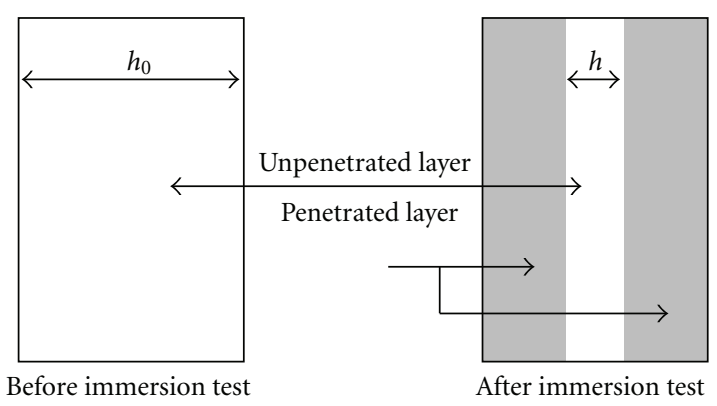

(b)

FIGURE 4: Schematic diagrams of sample (a) and typical micrograph (b) of EDS analysis.

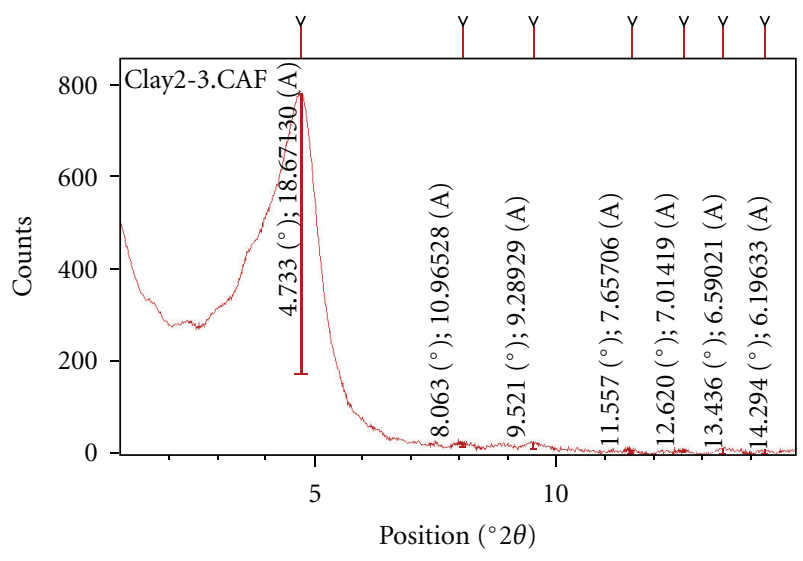

Figure 5: X-ray diffraction curve of organoclay.

spectroscopy JEOL JEM-5310LV was employed by investigating cross section of the immersed specimens as shown in Figure 4(a). Typical investigation by EDS is illustrated in Figure 4(b), where the line expresses the profile of the element $\mathrm{S}$ along depth from the surface. The penetration depth, which is the distance from surface to the level of the profile, is calculated by

$$
P_{d}=\frac{h_{0}-h}{2},
$$

where $P_{d}=$ penetration depth (meter), $h_{0}=$ unpenetrated layer at initial time (meter), and $h=$ penetrated layer at sampling time (meter).

\section{Results and Discussion}

3.1. Interlayer Distance (d-Spacing). X-ray diffraction curves of organoclay and $1 \mathrm{phr}$ epoxy/organoclay nanocomposite are illustrated in Figures 5 and 6 . The interlayer distance ( $d$-spacing) corresponding to the gap between clay layers is calculated according to Bragg's law: $n \lambda=2 d \sin \theta$. The supplied organoclay has a single sharp peak at $2 \theta=4.7^{\circ}$ as shown in Figure 5, which corresponds to $d$-spacing of $1.87 \mathrm{~nm}$. In the case of all nanocomposites, clear peaks were

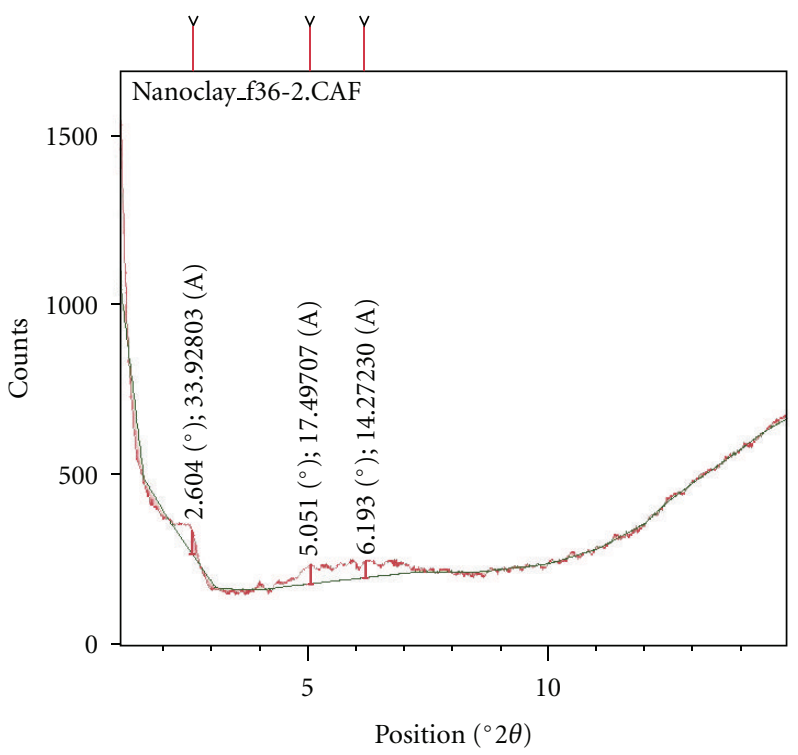

FIgURE 6: X-ray diffraction curve of 1 phr epoxy/organoclay nanocomposite under high-speed mixing method.

not detected except the nanocomposite under high speed mixing method. Figure 6 shows that the nanocomposite via high-speed mixing was found to intercalate and increase the $d$-spacing to $3.39 \mathrm{~nm}(2 \theta=33.9$ degree $)$. These results show two considered pieces of information: firstly, organoclay is significantly intercalated by epoxy resin, and secondly, due to the high degree of shear involved the breakup of large clay galleries into smaller ones took place and therefor increased clay interlayer distance.

3.2. Corrosion Behavior. All specimens: neat resin (EP), normal mixing (NMA), shear mixing (RHA), and highspeed mixing (DME) nanocomposites were immersed in $10 \%$ of sulfuric acid solution at fixed temperature, $60^{\circ} \mathrm{C}$. The aim of this analysis is to determine whether the diffusion of sulfuric acid through epoxy/organoclay nanocomposites is following Fick's law, and to investigate weight change of samples which are immersed in 10 mass \% sulfuric acid 


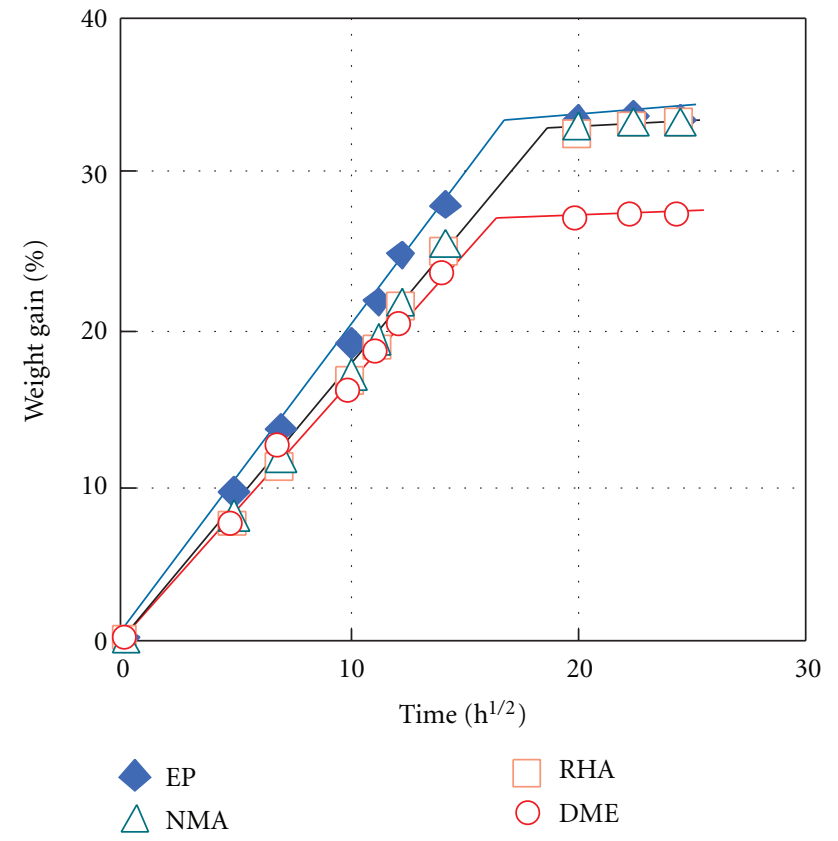

FIgURE 7: Weight change of neat epoxy (EP), normal mixing (NMA), shear mixing (RHA), and high-speed mixing (DME) nanocomposite in terms of square root of time in $10 \%$ of sulfuric acid solution at $60^{\circ} \mathrm{C}$.
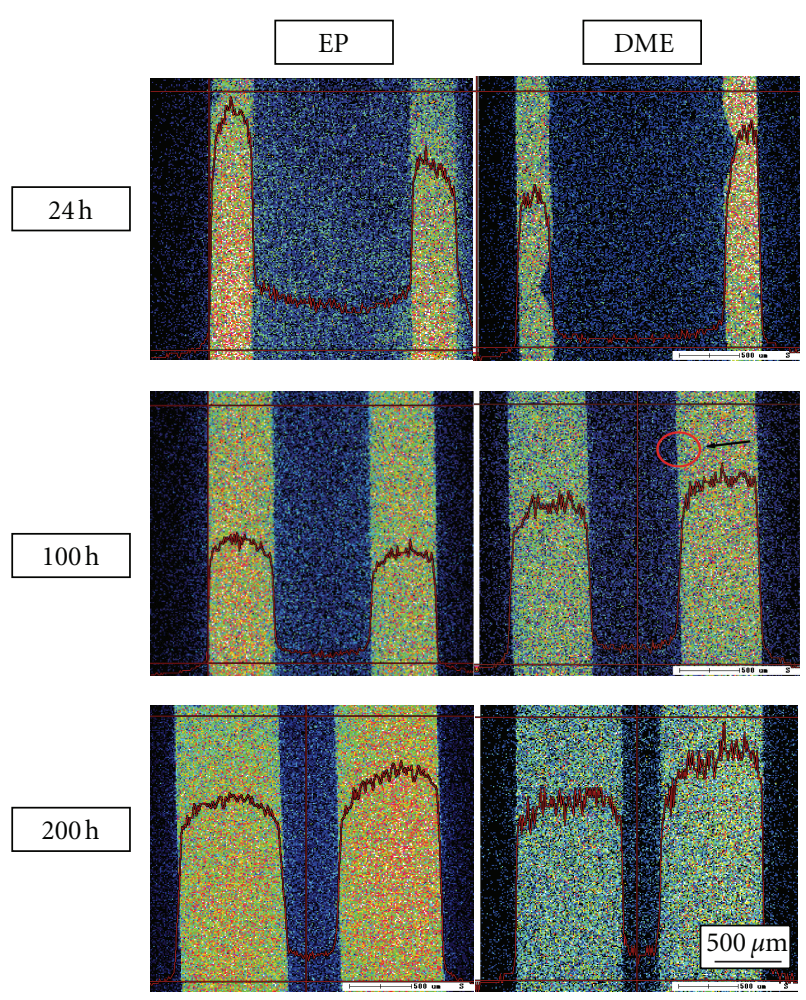

Figure 8: Penetration profiles of sulfur of neat epoxy (EP) and highspeed mixing (DME) nanocomposite at different immersion time under $10 \%$ of sulfuric acid solution.
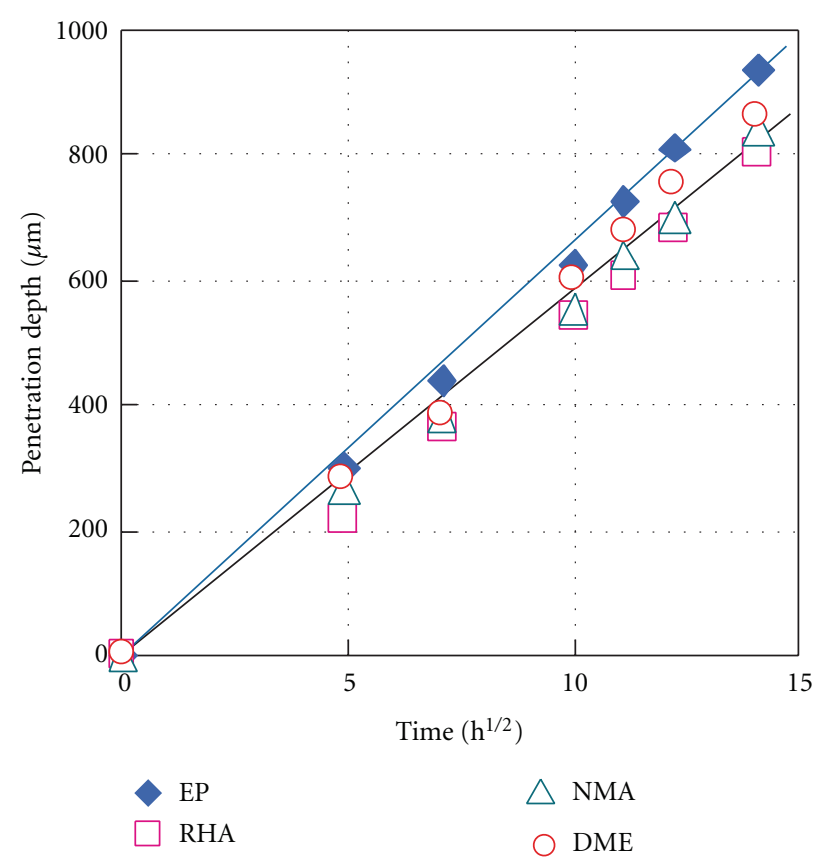

Figure 9: Penetration depth of neat epoxy and epoxy/organoclay nanocomposite under different mixing methods in terms of square root of time.

solution at $60^{\circ} \mathrm{C}$ as a function of square root of immersion time in Figure 6.

In this report, corrosion in the composite is described by its weight change behavior and penetration depth. The diffusion behavior of sulfuric acid in both neat resin and nanocomposites follows Fick's law in weight change. As Figure 7 shows, all the samples initially were linearly increased along to the root immersion time. So, all the specimens started to be filled with sulfuric acid solution by diffusion, leading to equilibrium. The difference of weight saturation of high-speed mixing method compared to normal mixing and three-roll calender mixing is considerably large, more than $5 \%$ of total specimen mass. It is considered that the enhancement of corrosion property is related to the degree of dispersion of the clay platelets.

In order to discuss the behavior in details, all samples have almost similar penetration rates; however, high-speed mixing sample and neat epoxy resin reached equilibrium at similar time and earlier compared to normal mixing and shear mixing samples. It would be for the reason that layered clays themselves do not assist to improve anticorrosion performance as labyrinth effect in terms of penetration rate, moreover, the conventional and intercalated clays act as a moisture scavenger by absorbing the solution into themselves. As a result, both conventional and intercalated clay structures, which still remain layer-layer structure, in the epoxy matrix via normal and shear mixing occur the second absorption and postpone the equilibrium to longer time.

Therefore, high degree of intercalation/exfoliation of high-speed mixing specimen has the lowest weight saturation of the other two methods. This suggests that the mixing method of clay, especially via high-speed mixing method, 


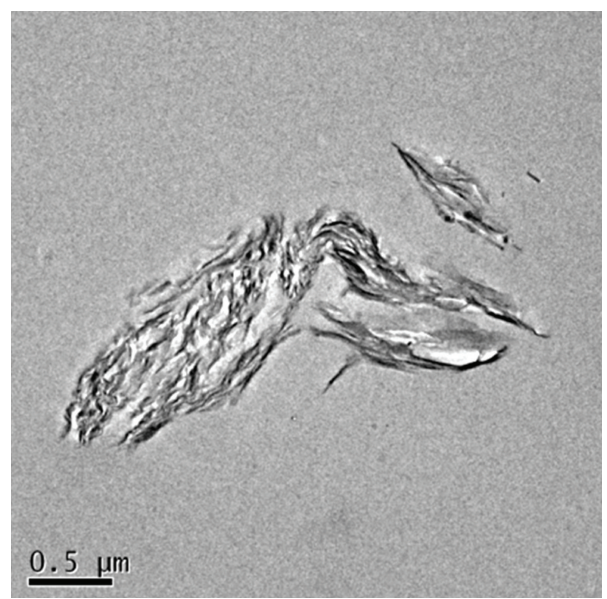

(a)

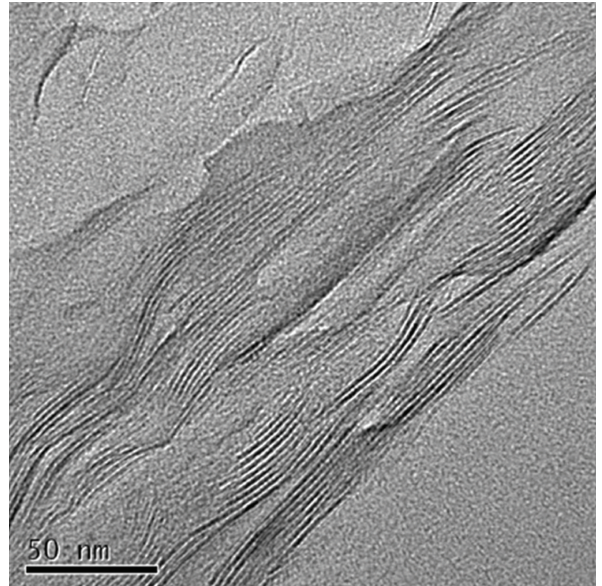

(b)

FIGURE 10: TEM images of epoxy/clay nanocomposites via normal mixing method at different magnifications.

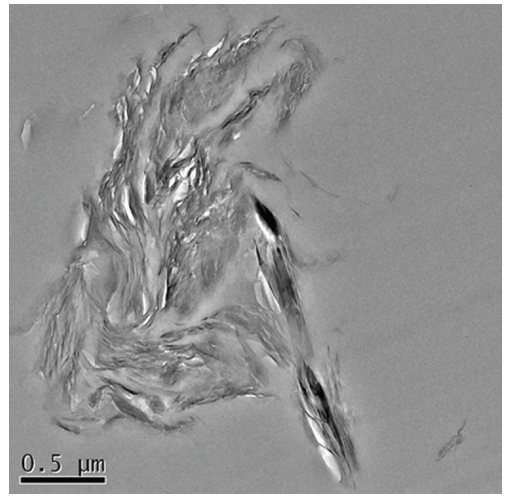

(a)

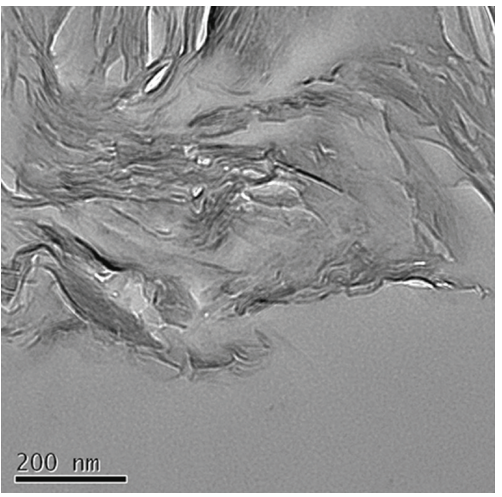

(b)

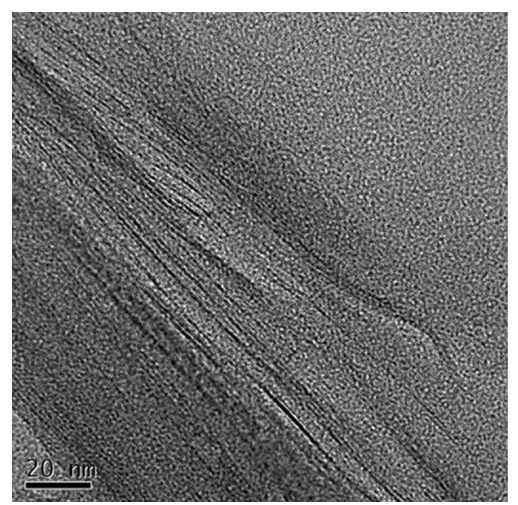

(c)

FIGURE 11: TEM images of epoxy/clay nanocomposites via shear mixing method at different magnifications.

significantly affects corrosion behavior in terms of solution equilibrium. The behavior can be explained that the random orientation of clay plates in the bulk material, which is reasonably effective in improving property, especially corrosion resistance. As a result, it could be effectively against penetration and weight uptake.

Penetration profiles of sulfur of neat epoxy and one of three mixing methods, high-speed mixing (DME) nanocomposite at different immersion time under $10 \%$ of sulfuric acid solution using EDS analysis, are shown in Figure 8. There are two areas from EDS micrograph: (1) unpenetrated layer and (2) penetrated layer. The lines in Figure 8 express the penetration profiles of element $S$ along the depth from surface. For deeply analyzing the penetration profiles of sulfur element, penetrated area in nanocomposite shows slightly less than neat epoxy resin for all immersion time, except after reaching saturation. The result implies that nanoclay particles improve barrier property by physically impeding the movement of penetrant molecules through the matrix which are explained later in mechanism of corrosion section.
Sulfur penetration depth of neat resin and epoxy/organoclay nanocomposite versus square root of time is shown in Figure 9. The penetration depth obtained from EDS analysis is calculated according to (2). It notices that nanocomposites have a lower penetration depth as compared to the neat resin. As we expected, the nanoclay would act as a barrier for the diffusion of acid solution in the nanocomposites. Comparing three various mixing methods, penetration depths of these nanocomposites were not expectedly different. It would be discussed that the equal nanofiller content for all nanocomposites and mixing methods does not play an important role in the penetration depth.

3.3. Morphology. Figure 10 shows TEM micrographs of epoxy/organoclay nanocomposite via normal propeller mixing method at different magnifications. As expected, normal mixing method has a small shear force for clay exfoliation but distribute uniformly in epoxy resin. The results show that clay galleries visually agglomerate (Figure $10(a)$ ), and the gap between clay layers in the epoxy matrix keeps naturally tight (Figure 10(b)). In order to intercalate/exfoliate, it 


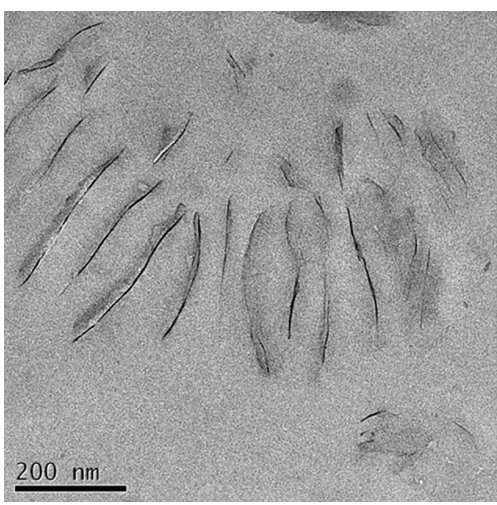

(a)

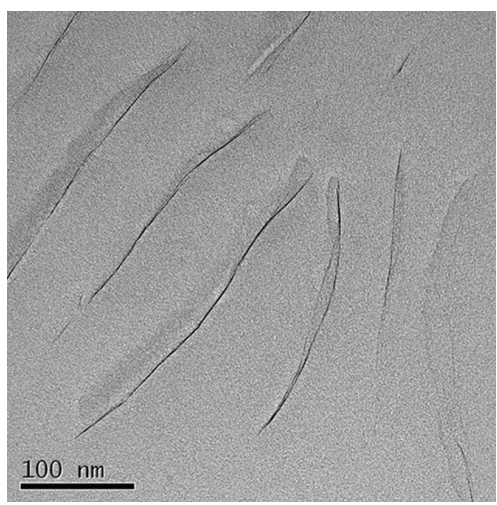

(b)

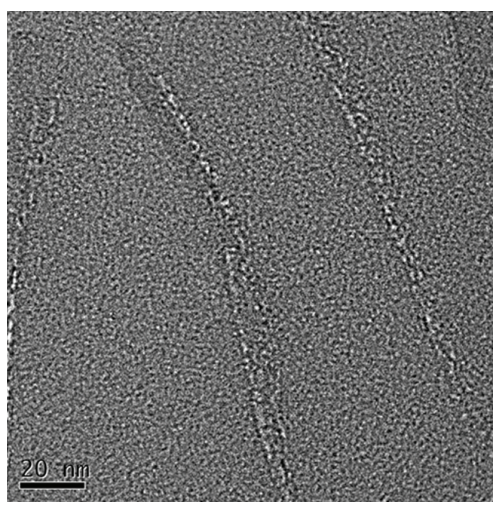

(c)

FIGURE 12: TEM images of epoxy/clay nanocomposites via high-speed mixing method at different magnifications.

requires energy to break large clay galleries into smaller ones and peel each platelet one after the others. It is possible to notice that shear force from normal propeller mixing is not high enough to break up large clay stacks into smaller stacks of clay platelets.

Figure 11 shows TEM images of epoxy/clay nanocomposites via shear mixing method at different magnifications. The TEM micrographs show that clay galleries have less tight agglomeration compared to normal mixing (Figures 11(a) and 11(b)). The clay interlayer distance is larger than normal mixing especially at the edge area (Figure 11(c)). It suggests that shear force affects clay dispersion, and further continuing to apply shear force to intercalated clay particle could develop clay exfoliation.

Figure 12 shows TEM images of epoxy/clay nanocomposites via high-speed mixing method at different magnifications. All TEM results show the well dispersion of clay layers with noticed large interlayer distance. The $d$ spacing of clay in the epoxy matrix via the high-speed mixing method is larger and shows excellent exfoliation with the clay platelets parallel to each other, compared to the other methods, because of the high-speed homogenizer. The results obviously confirm that high-speed mixing method leads to a clay exfoliation, and the mixing method has an effect on clay dispersion in epoxy resin.
3.4. Mechanism of Corrosion Protection against Environmental Liquid Penetration. Figure 13 shows model of three kinds of nanocomposites made by normal mixing, shear mixing, and high-speed mixing based on TEM observation. The black dot represents crosslink between epoxy resin and curing agent, and gray dot represents onium ion.

Normal mixing includes randomly dispersed stacked fillers with small gaps as shown in Figure 13(a). Shearmixing-dispersed clay stacks into smaller stacks of clay platelets as intercalation with larger interlayer distance compared to normal mixing as shown in Figure 13(b). Highspeed mixing results in intercalated/exfoliated layered fillers as shown in Figure 13(c). Due to the low degree of shear via normal and shear mixing involved, the energy is not enough to break clay stacks and hence dose not enhance degree of intercalation/exfoliation. On the other hand, due to the higher degree of shear via high-speed mixing involved the breakup of tight stacks into separated platelets took place and hence increased degree of intercalation/exfoliation.

Moreover, layered clays benefit in fixing the movement of polymer network. Onium ions which is contained on the surface of treated clay nanofillers would react with epoxy monomers (as the gray dots in illustration) and form crosslink. These phenomena could affect to decrease polymer mobility. Consequently, it would be expected to declaim weight uptake of the materials. 


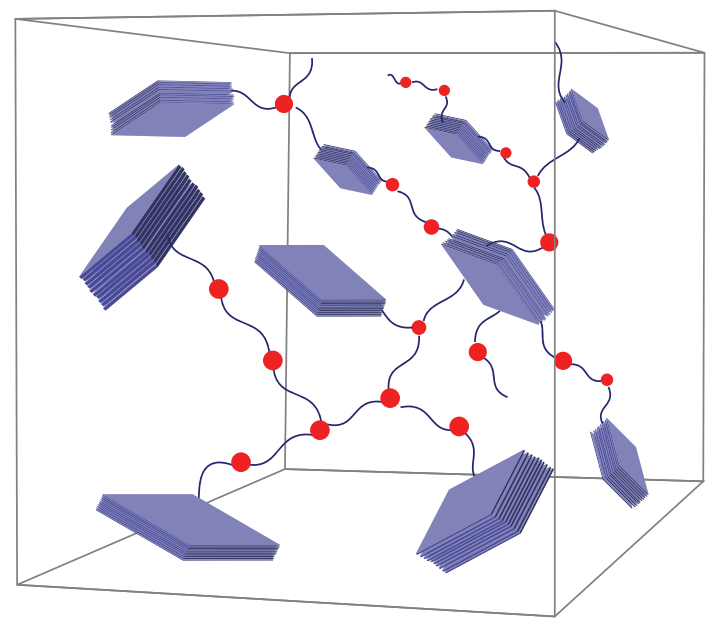

(a) Normal mixing

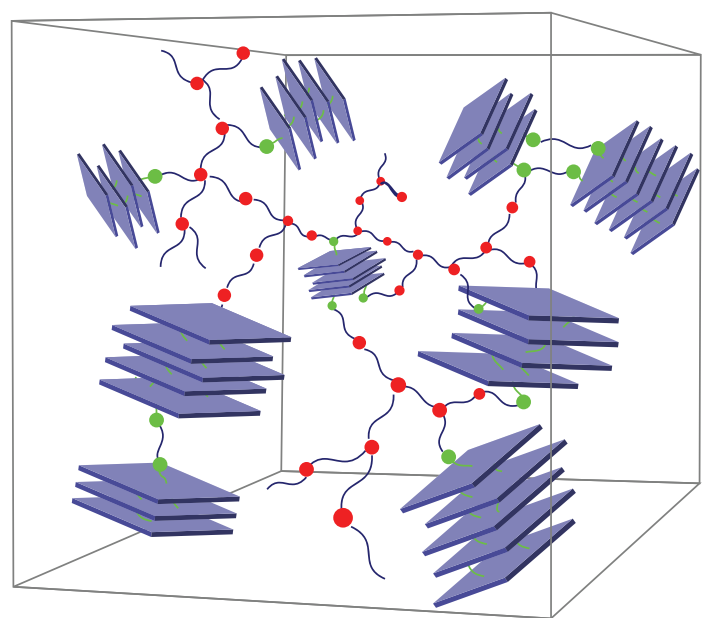

(b) Shear mixing

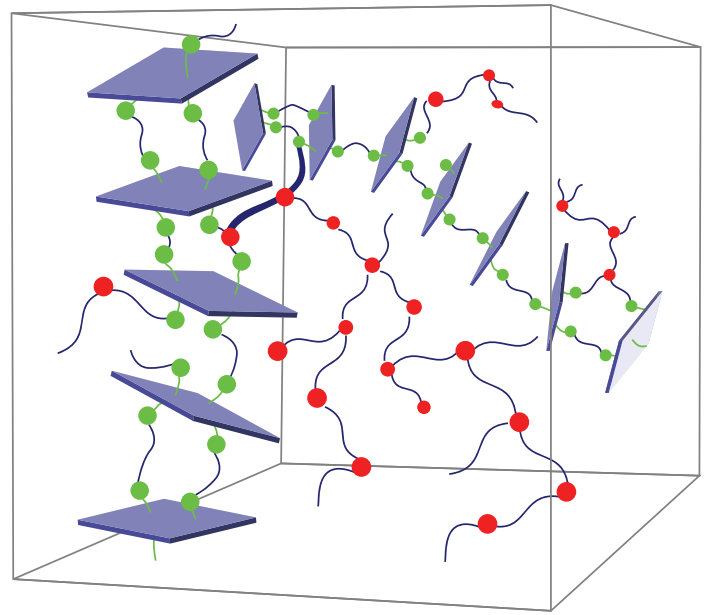

(c) High speed mixing

FIGURE 13: Model of three kinds of nanocomposites made by normal mixing, shear mixing, and high-speed mixing. (Black dot represents crosslink between epoxy resin and curing agent, and gray dot represents onium ion.)

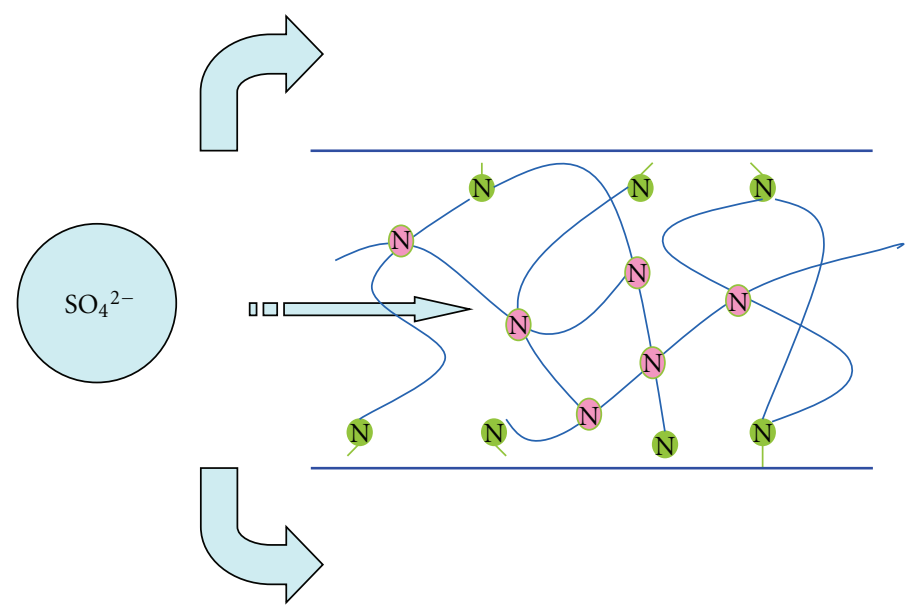

FIGURE 14: Mechanism of sulfuric acid diffusion in epoxy network and intercalated layered filler. 
Solution equilibrium of epoxy/organoclay nanocomposite via high-speed mixing method is noticeably different compared to other samples as illustrated in Figure 7. Highspeed mixing sample which contain exfoliated nanoclay structure in the epoxy matrix as shown in Figure 13(c) has lower weight uptake than other samples. This phenomenon may be explained by the following mechanism. As illustrated in Figure 14, epoxy polymerization may occur with onium ions on clay layers; after that, it reacts with initially amine organic agent and makes epoxy network in the layer-layer gaps. The resulting polymer network included in the layers is difficult to move compared with the bulk epoxy network, so the penetration in the gaps will be slower. Then, initially penetrant may diffuse into bulk where clay influence is small and after that into the gaps. On the other hand, exfoliated clay structure could be more fixed in polymeric matrix compared to intercalated and conventional clay structures. Therefore, bulk matrix resin would decrease mobility and limited the penetration. These phenomena lead to lower weight uptake of sulfuric acid as shown by exfoliated clay structure.

\section{Conclusion}

Mixing method of epoxy nanocomposites plays an important role in clay dispersion in epoxy resin and is a main key parameter of epoxy/organoclay nanocomposites in the improvement of corrosion performance such as weight change, penetration depth, penetration profile and size of penetration depth. In order to obtain knowledge of anticorrosion performance of epoxy nanocomposites, three sample composites were prepared by different three mixing methods. Corrosion behavior was investigated under immersion test, and evaluated by penetration depth and penetration profile. All samples have almost similar penetration rates. On the other hand, high-speed mixing sample and neat epoxy resin reached equilibrium at similar time and earlier compared to normal mixing and shear mixing samples. Epoxy/organoclay nanocomposite preparation under high speed mixing method which creates exfoliated clay dispersion in the epoxy matrix performs better corrosion resistance compared to normal and shear mixing methods regarding to weight gain and penetration depth.

\section{Acknowledgment}

The authors would like to thank the Center for Advanced Materials Analysis, National University Corporation Tokyo Institute of Technology, for XRD and TEM analysis.

\section{References}

[1] P. C. Lebaron, Z. Wang, and T. J. Pinnavaia, "Polymer-layered silicate nanocomposites: an overview," Applied Clay Science, vol. 15, no. 1-2, pp. 11-29, 1999.

[2] T. J. Pinnavaia and G. W. Beall, Polymer-Clay Nanocomposites, John Wiley \& Sons, Hoboken, NJ, USA, 2000.

[3] Z. Wang and T. J. Pinnavaia, "Hybrid organic-inorganic nanocomposites: exfoliation of magadiite nanolayers in an elastomeric epoxy polymer," Chemistry of Materials, vol. 10, no. 7, pp. 1820-1826, 1998.

[4] A. Okada, Y. Fukushima, M. Kawasumi et al., "Composite Material and Process for Manufacturing Same," U.S. Patent 4, 739, 007, 1988.

[5] I. Curtu and D. Luca Motoc, "Theoretical-experimental comparisons of multi-phase composite materials elastic coefficients retrieved from tensile, compressive and bending tests. Influencing factors," Materiale Plastice, vol. 45, no. 4, pp. 366$371,2008$.

[6] A. Esfandiari, H. Nazokdast, A. S. Rashidi, and M. E. Yazdanshenas, "Review of polymer-organoclay nanocomposites," Journal of Applied Sciences, vol. 8, no. 3, pp. 545-561, 2008.

[7] A. Esfandiari, "The statistical investigation of mechanical properties of $\mathrm{PP} /$ natural fibers composites," Fibers and Polymers, vol. 9, no. 1, pp. 48-54, 2008.

[8] C. Shan, Z. Gu, L. Wang et al., "Preparation, characterization, and application of NR/SBR/Organoclay nanocomposites in the tire industry," Journal of Applied Polymer Science, vol. 119, no. 2, pp. 1185-1194, 2011.

[9] K. Sterky, H. Jacobsen, I. Jakubowicz, N. Yarahmadi, and T. Hjertberg, "Influence of processing technique on morphology and mechanical properties of PVC nanocomposites," European Polymer Journal, vol. 46, no. 6, pp. 1203-1209, 2010.

[10] K. Sterky, T. Hjertberg, and H. Jacobsen, "Effect of montmorillonite treatment on the thermal stability of poly(vinyl chloride) nanocomposites," Polymer Degradation and Stability, vol. 94, no. 9, pp. 1564-1570, 2009.

[11] A. Usuki, M. Kawasumi, Y. Kojima, A. Okada, T. Kurauchi, and O. Kamigaito, "Swelling behavior of montmorillonite cation exchanged for $\omega$-amino acids by $\varepsilon$-caprolactam," Journal of Materials Research, vol. 8, no. 5, pp. 1174-1178, 1993.

[12] A. Okada and A. Usuki, "The chemistry of polymer-clay hybrids," Materials Science and Engineering C, vol. 3, no. 2, pp. 109-115, 1995.

[13] K. Yano, A. Usuki, and A. Okada, "Synthesis and properties of polyimide-clay hybrid films," Journal of Polymer Science A, vol. 35, no. 11, pp. 2289-2294, 1997.

[14] E. Sancaktar and J. Kuznicki, "Nanocomposite adhesives: Mechanical behavior with nanoclay," International Journal of Adhesion and Adhesives, vol. 31, no. 5, pp. 286-300, 2011.

[15] R. A. Vaia, K. D. Jandt, E. J. Kramer, and E. P. Giannelis, "Microstructural evolution of melt intercalated polymerorganically modified layered silicates nanocomposites," Chemistry of Materials, vol. 8, no. 11, pp. 2628-2635, 1996.

[16] L. Wang, K. Wang, L. Chen, Y. Zhang, and C. He, "Preparation, morphology and thermal/mechanical properties of epoxy/nanoclay composite," Composites A, vol. 37, no. 11, pp. 1890-1896, 2006.

[17] E. Sancaktar and J. Kuznicki, "Nanocomposite adhesives: mechanical behavior with nanoclay," International Journal of Adhesion and Adhesives, vol. 31, no. 5, pp. 286-300, 2011.

[18] W. Keyoonwong, M. Kubouchi, T. Sakai, and S. Aoki, "Preparation of exfoliated epoxy/clay nanocomposite and its thermal \& mechanical properties," in Proceedings of the International Symposium on Engineering, Energy and Environment (ISEEE09 '09), pp. 158-163, Rayong, Thailand, 2009.

[19] N. Abacha, T. Sakai, K. Tsuda, and M. Kubouchi, "Preparation and performance under corrosive environment of epoxynanocomposite," Key Engineering Materials, vol. 353-358, no. 3, pp. 2167-2170, 2007.

[20] J. M. Yeh, H. Y. Huang, C. L. Chen, W. F. Su, and Y. H. Yu, "Siloxane-modified epoxy resin-clay nanocomposite coatings with advanced anticorrosive properties prepared by a solution 
dispersion approach," Surface and Coatings Technology, vol. 200, no. 8, pp. 2753-2763, 2006.

[21] T. D. Ngo, M. T. Ton-That, S. V. Hoa, and K. C. Cole, "Effect of temperature, duration and speed of pre-mixing on the dispersion of clay/epoxy nanocomposites," Composites Science and Technology, vol. 69, no. 11-12, pp. 1831-1840, 2009.

[22] H. T. Rana, R. K. Gupta, H. V. S. GangaRao, and L. N. Sridhar, "Measurement of moisture diffusivity through layered-silicate nanocomposites," American Institute of Chemical Engineers Journal, vol. 51, no. 12, pp. 3249-3256, 2005.

[23] N. Abacha, M. Kubouchi, T. Sakai, and K. Tsuda, "Diffusion behavior of water and sulfuric acid in epoxy/organoclay nanocomposites," Journal of Applied Polymer Science, vol. 112, no. 2, pp. 1021-1029, 2009. 

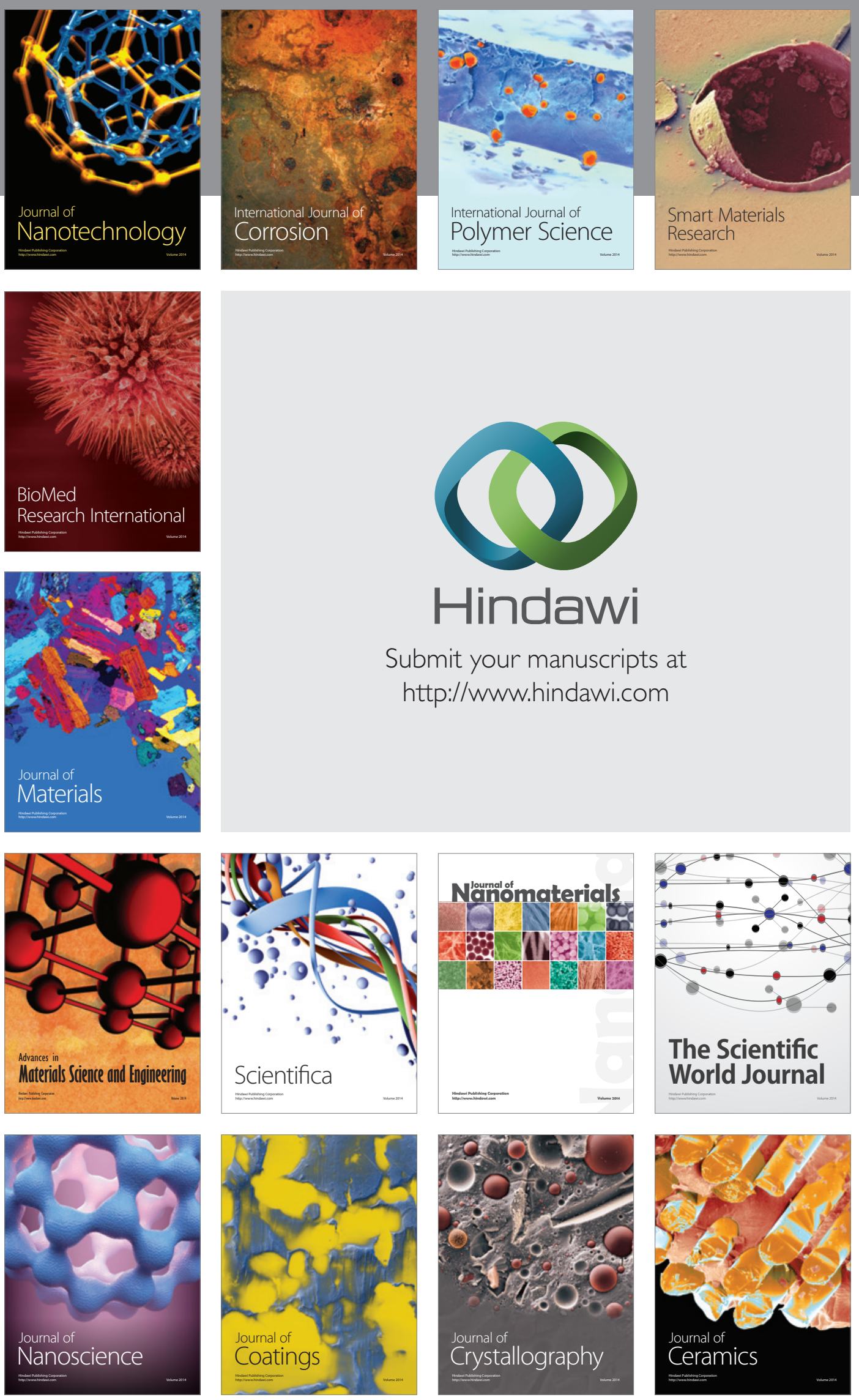

The Scientific World Journal

Submit your manuscripts at

http://www.hindawi.com

\section{World Journal}

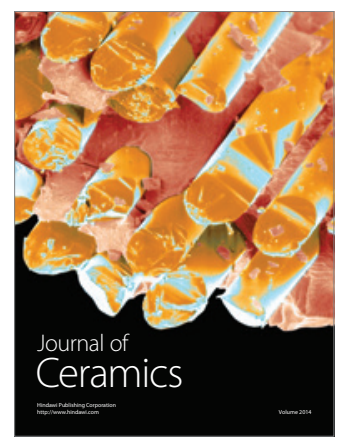

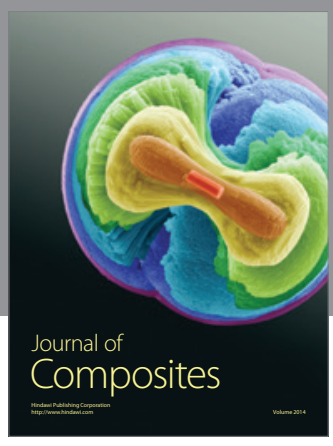
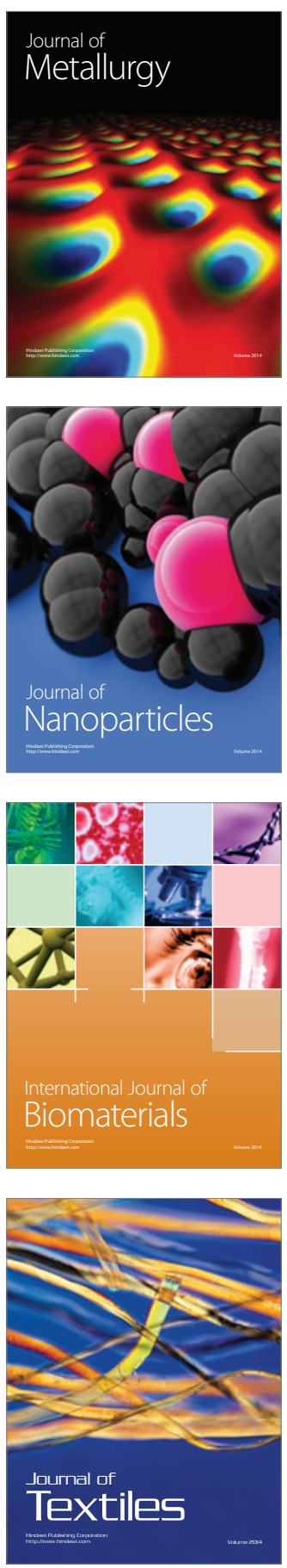